\title{
Aorto-renal bifurcation stenting in a juvenile non-specific aorto-arteritis: case report
}

\author{
Santosh Kumar Sinha', Vinay Krishna', Narendra Khanna', Lawrence Rajan², \\ Mukesh Jitendra Jha', Vikas Mishra', Mohammad Asif', Ramesh Thakur', Mahmadula Razi' \\ 'Department of Cardiology, LPS Institute of Cardiology, Kanpur, India \\ ${ }^{2}$ Interventional Cardiologist, Department of Cardiology, Community Health Centre, Kentucky, USA
}

\begin{abstract}
Takayasu Arteritis (TA) is a granulomatous inflammation of unknown aetiology affecting the aorta and its major branches with usual affliction among patients younger than 50 years and rarely among children. We present a 7-years old boy referred for evaluation of hypertension. He had a significant blood pressure difference between right arm, left arm and lower limbs. Computed tomography imaging of thorax and abdomen showed stenosis of left subclavian artery, left renal artery and juxtarenal aorta which was subsequently confirmed on aortogram. He underwent percutaneous endovascular therapy with aorto-renal bifurcation stenting with reduction of blood pressure and gradient. Renal angioplasty with stenting remains a challenging procedure in patients with tight ostial lesion, and juxtarenal aortic involvement in lieu of precise stent placement and avoiding side branch occlusion.
\end{abstract}

Key words: aorto-renal bifurcation stenting, computed tomography, juvenile takayasu arteritis, percutaneous endovascular therapy, secondary hypertension

Acta Angiol 2018; 24, I: 25-29

\section{Introduction}

Takayasu Arteritis is a chronic inflammatory disease that involves the aorta, its branches and the pulmonary arteries causing the varying degree of stenosis, dilatation or both. Despite being the third most frequent vasculitis in childhood, the occurrence of juvenile TA is scarce although youngest to be reported was 6-month old baby [I]. It is the commonest cause of renovascular hypertension in Asian children as thoracoabdominal aorta is mainly involved in patients from Korea and India [2]. The usual symptom is due to hypertension, heart failure or a neurological event whereas claudication, bruit or a missing pulse in an asymptomatic child are quite uncommon thus the delay in its early diagnosis and consequently resulting in serious complications. TA in children is associated with higher morbidity and mortality than adults [3]. Hypertension in Takayasu Arteritis results from renal artery stenosis or aortic narrowing and aortic fibrosis. Renal arterial stenosis may be bilateral and usually coexists with aortic involvement [4]. It involves the ostia of the renal arteries sparing the intrarenal vasculature and small vessels.

\section{Case report}

A 7-year old boy was admitted for evaluation of hypertension. There was no history of valvular heart disease. On examination, he looked small for his age with body weight $17 \mathrm{~kg}$, conscious and afebrile. Blood pressure on right arm, left arm and both legs were 136/86, 106/82 and 68/52 $\mathrm{mm} \mathrm{Hg}$ respectively. On examination, there was absent pulse on tibial and femoral arteries on both legs. Other examination findings were not remarkable. Therefore, blood pressure was labelled as stage II hypertension for this child [5]. The difference in blood pressure of $\geq 20 \mathrm{~mm} \mathrm{Hg}$ between the upper and lower extremities suggested juvenile TA.

Address for correspondence: Santosh Kumar Sinha, Department of Cardiology. LPS Institute of Cardiology, G.S.V.M. Medical College Uttar Pradesh, 208002 Kanpur, Indie, e-mail: fionasan@rediffmail.com 


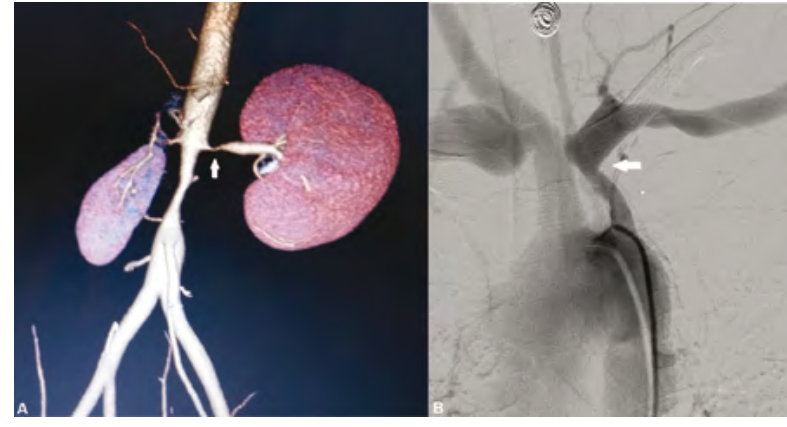

Figure I. CT angio of abdomen showing critical stenosis of left renal artery and atrophic right kidney (white arrow, A); Thoracic DSA showing stenosis of left subclavian artery (white arrow, B)

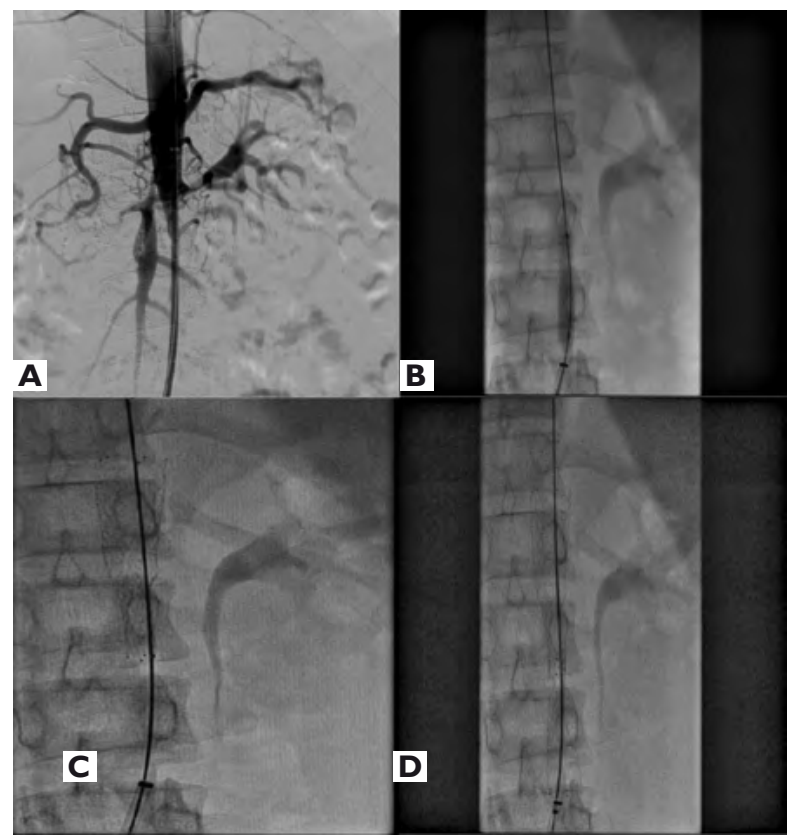

Figure 2. A - abdomen DSA showing narrowing of descending thoracic and juxrarenal abdominal aorta, and left renal artery; B - predilatation of aorta by semicompliant balloon; C - endovascular deployment of proximal stent; D - distal stent overlapping with proximal stent in juxta renal aorta

Laboratory investigations showed mild anaemia with haemoglobin II.I mg/dl, normal erythrocyte sedimentation rate (ESR) and c-reactive protein (CRP). Chest skiagram and ophthalmologic evaluation were normal. Computed Tomography (CT) scan of the thorax and abdomen showed narrowing of the mid aorta, left subclavian artery and ostial involvement of left renal artery with atrophic right kidney (Fig. IA). An aortography revealed narrowing of descending thoracic and juxrarenal abdominal aorta, left subclavian artery and ostial involvement of left renal artery with $90 \%$ discrete stenosis (Fig. IB, 2A). On gradual catheter pullback, transaortic pressure gradient was $80 \mathrm{~mm} \mathrm{Hg}$. Based on

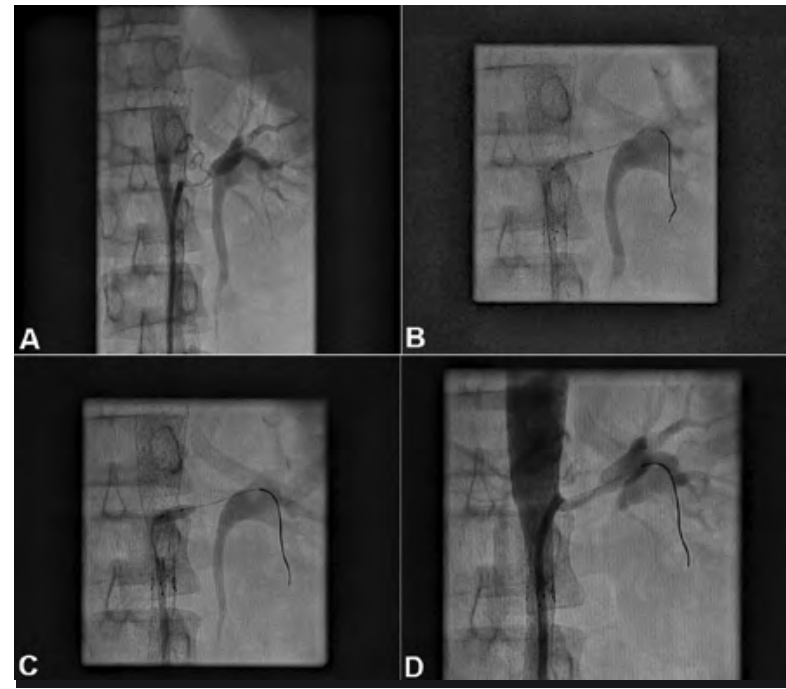

Figure 3. A - left renal artery was cannulated with renal double curve (RDC) guiding catheter; B-D - predilatation of lesion with semi compliant balloon after wiring with runthrough coronary guide wire

EULAR (European League Against Rheumatism)/PRES (Paediatric Rheumatology European Society) criteria, he was diagnosed as TA in remission stage [6]. Patient was planned for percutaneous transluminal angioplasty (PTA) for the treatment of stenosed descending thoracic and abdominal aorta and renal artery dilatation followed by bailout stenting. Access was gained through the right femoral artery (retrograde approach) using micropuncture set. $6 \mathrm{~F}$ long sheath was advanced through a $0.035^{\prime \prime}$ terumo guidewire (Terumo, Japan). Sequential predilatation was performed, by $10 \times 40 \mathrm{~mm}$, and $12 \times$ $40 \mathrm{~mm}$ Mustang balloon (Boston Scientific, USA) up to $10 \mathrm{~atm}$ pressure (Fig. 2B). Despite adequate dilatation, trans-aortic gradient was $40 \mathrm{~mm} \mathrm{Hg}$. Aorta was stented by deploying proximally Epic $^{\text {TM }} 19 \times 60 \mathrm{~mm}$ and distally Epic $^{T M} 19 \times 40 \mathrm{~mm}$ at $12 \mathrm{~atm}$ and 14 atm pressure with one strut overlap in between (Fig. 2C, D). The overlapping part was further dilated by the same distal stent balloon at 14 atms pressure. Aortography post angioplasty was performed with good results with no dissections. Residual trans-aortic pressure gradient was $14 \mathrm{~mm} \mathrm{Hg}$. Left renal artery was cannulated with $6 \mathrm{~F}$ renal double curve (RDC) guiding catheter (Cordis Corp., USA) (Fig. 3A). 0.014" runthrough wire (Terumo, Japan) was parked distally (Fig. 3B). Lesion was predilated by $2.5 \times 10 \mathrm{~mm}, 3 \times 10 \mathrm{~mm}$ Maverick semi-compliant balloon (Boston Scientific, USA) at 15 atms and $3.5 \times$ 12 noncompliant balloon at 20 atms pressure to open up the lesion as it appeared fibrotic (Fig. 3 C, D). It was stented with $5 \times 19 \mathrm{~mm}$ Hippocampus bare metal stent (Medtronic, USA) with I-2 mm of stent overhanging into the aorta to ensure ostial coverage and was deployed at 


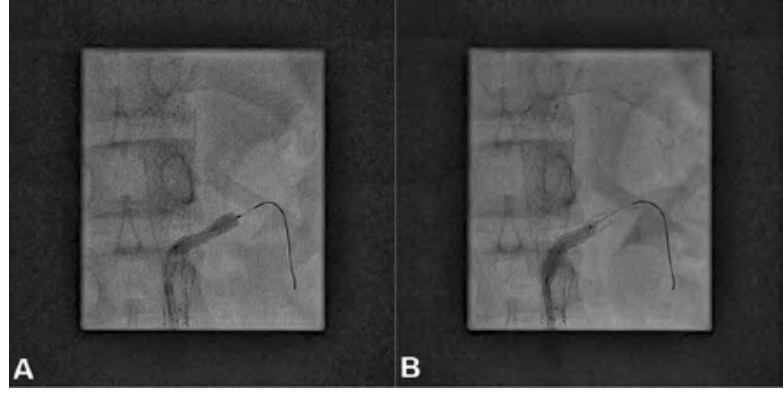

Figure 4. A - stenting of left renal artery with $7 \times 19 \mathrm{~mm}$ Hippocampus bare metal stent with I-2 mm of stent overhanging in the aorta; $\mathbf{B}$ - flaring of the ostia

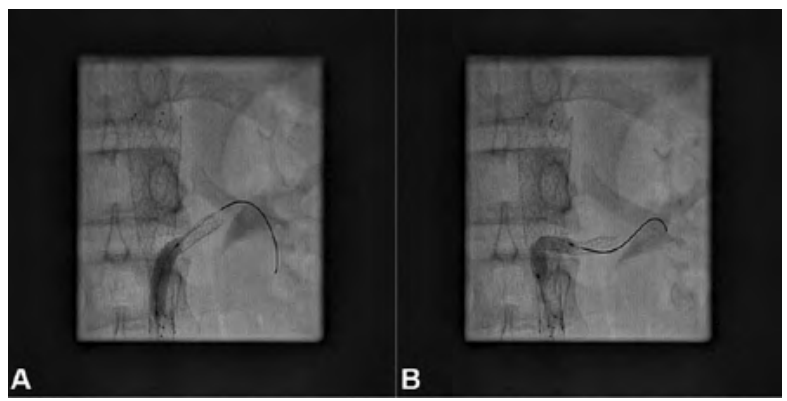

Figure 5. Funelling of ostia by further pulling and pushing up the balloon

9 atms pressure (Fig. 4A). The stent-balloon assembly was further pulled into the aorta and inflated at 14 atms to flare the ostia (Fig. 4B, 5A). The same balloon was further pushed up along the guiding catheter and inflated at 16 atms to properly flare and funnell the ostia (Fig. $5 B)$. It was done to ensure that guiding catheter could be coaxially placed in future in case any restenosis occurs. The final angiogram revealed optimally deployed stents (Fig. 6, 7A-C). The patient was started on aspirin 75 $\mathrm{mg}$, amlodipine $10 \mathrm{mg}$ and hydrochlorothiazide $12.5 \mathrm{mg}$ once daily and subsequently discharged. After 6 months' follow-up, blood pressure was stable at $100 / 60 \mathrm{~mm} \mathrm{Hg}$ and $\mathrm{CT}$ angiogram revealed well expanded and patent stents (Fig. 7D).

\section{Discussion}

The onset of illness in TA may be earlier, including in childhood but rarely in infancy [3]. Hypertension in patients with TA is either detected incidentally or present with complications such as hypertensive encephalopathy or heart failure. Patients with juvenile TA generally present below the age of 8 years with non-specific systemic symptoms such as fever and weight loss in contrast to adult patients, who usually present with hypertension, decreased peripheral artery pulsations or claudication of the extremities. Vascular involvement is similar to adult population though less frequent.

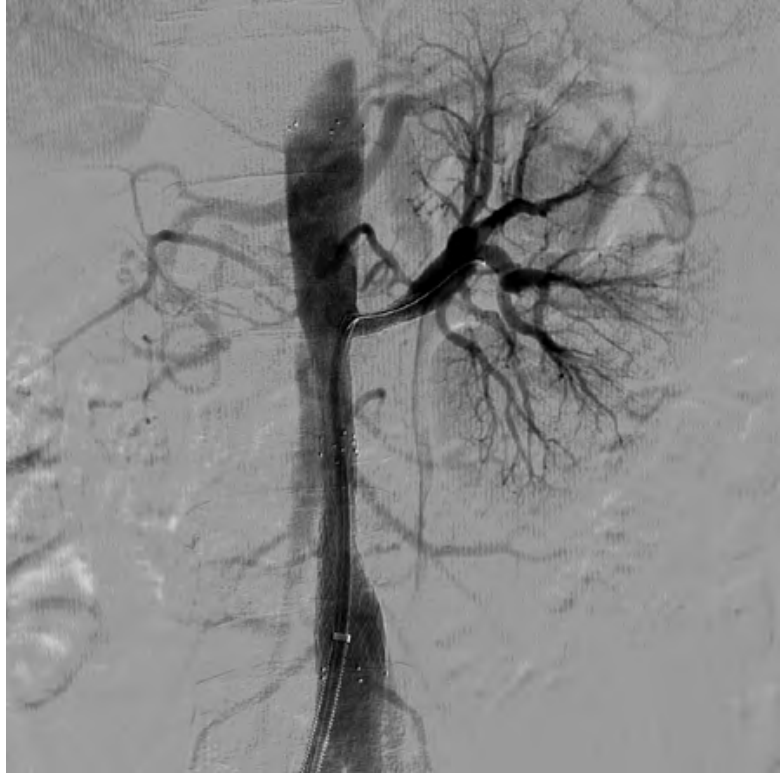

Figure 6. Abdomen DSA showing optimally deployed renal stent with proper ostial coverage

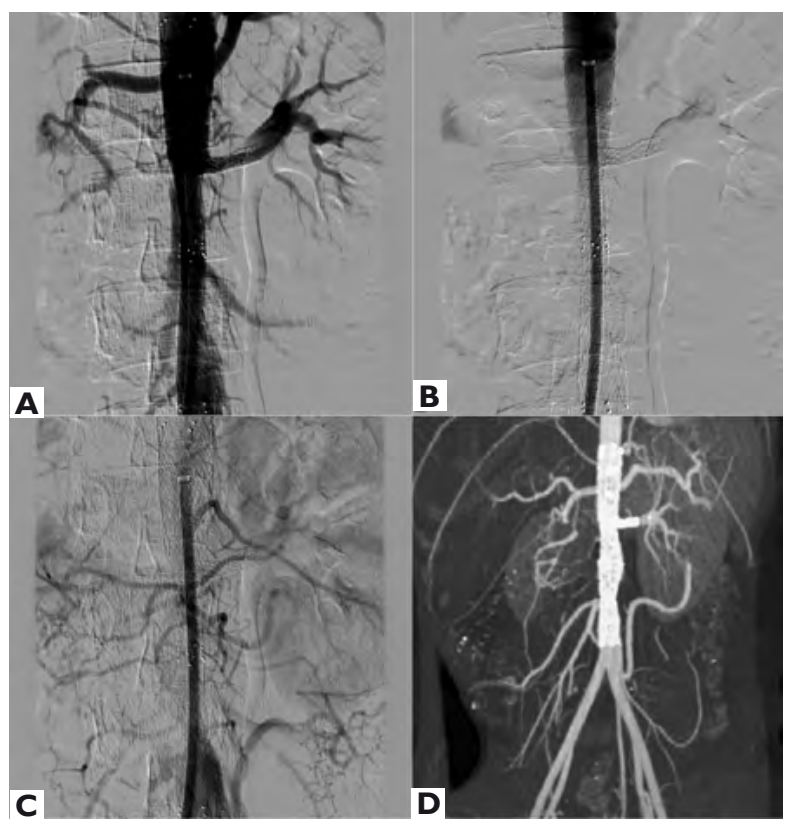

Figure 7. A-C — abdomen DSA showing optimally deployed stents; $\mathbf{D}-\mathrm{CT}$ angiogram showing well expanded and patent stents on 6 months follow up

Assessing disease activity in patients with Takayasu arteritis is frequently challenging since clinical, biologic, and radiologic information do not always correlate. In our case, TA was diagnosed and active stage was ruled out on the basis of EULAR/PRINTO/ PRES/Prospective study criteria established by Kerr et al. [7, 8] which includes ESR $>20 \mathrm{~mm}$ per hour or CRP above normal as acute phase reactant. It is important to identify active disease since this requires immunosuppressive treatment, but its role in the late 
stage of the disease is unclear when a risk-benefit balance must be made.

Clinicians currently combine clinical features with acute phase reactants such as the erythrocyte sedimentation rate and/or $C$ reactive protein; imaging techniques such as positron emission tomography (PET-CT) [9], contrast-enhanced magnetic resonance imaging (MR) [I0], and CT angiography [II], and formal digital subtraction arteriography (DSA), perceived by most to be the gold standard for defining lumenography to monitor for disease activity and for stenotic sequelae.

The uptake of I8F-fluorodeoxyglucose on PET imaging is reported to be highly sensitive and accurate method for assessing disease activity in patients with TA with the sensitivity and specificity of $73-100 \%$ and $83-92 \%$, respectively [12]. In our case, the absence of constitutional symptoms with normal ESR and CRP leads us to conclude that patient was not in active phase of the disease.

Digital subtraction catheter arteriography is of particular importance in the assessment of patients potentially requiring revascularization procedures such as angioplasty and/or stenting, or more invasive surgical interventions such as aortic bypass grafting which iscommonly required to provide relief from symptomatic ischaemia [13-15].

Pentraxin-3 (PTX3), a member of the superfamily of acute- phase proteins such as c-reactive protein (CRP) and serum amyloid $P$, has been shown to be more accurate than the ESR and CRP level for differentiating active from inactive disease in patients with previously diagnosed TA. In a cross-sectional study, PTX3 > I ng/ $\mathrm{mL}$ were more accurate than normal thresholds of CRP and ESR for defining disease activity [16]. Certainly, it may play a future role as a possible disease marker but needs to be assessed in a broader spectrum of patients whose disease activity is unknown or equivocal before recommending it clinically as pointed out by Danga et al. [16].

Initially, steroids are used as an immunosuppresant and cytotoxic agents are reserved for patients whose disease is either steroid resistant or relapsing. Methotrexate, azathioprine, and cyclophosphamide are among the drugs used in TA, with cyclophosphamide being reserved for patients with the most severe and refractory disease states. As our patient was in the state of remission, no immunosuppression was prescribed.

Percutaneous transluminal angioplasty (PTA) in children has high-success rate close to $90 \%$ [4, I7]. Important considerations in determining the overall efficacy of these procedures are the rates of restenosis after angioplasty. In the study among I 3 patients by Colyer et al. [18], an overall restenosis rate of $18 \%$ with a rate of $40 \%$ with balloon angioplasty alone wasnoted. Similarly, in a study by Zhu et al among 22 children which were followed up for 13 years, rate of restenosis was 4 I\% [ 19 ].
In another study among 33 children as reported by Shroff et al. [20] restenosis was reported among $40 \%$ who had undergone stenting over 20 years of follow up. The varying rate may be due to small patient sample or a significant selection bias, as only the most severe patients were referred for catheterization and intervention. The smaller diameter of the vessel and the possible effect of growth factors on the child's vasculature may account for the higher restenosis rate than reported in adult series. Therefore, stents have not been accepted for paediatric population despite significant restenosis rates following balloon angioplasty alone, due to inherent problems of prosthetic material in this population. They have been successfully used to treat occlusive dissecting flaps or aortic obstruction [ 17]. For ostial lesions, which are encountered most frequently, stenting is preferred to balloon dilatation as these lesions are elastic and respond poorly to balloon dilatation alone and associated with higher procedural success rate $(98 \%$ vs. $77 \%)$ and the lower rate of the restenosis (I7\% vs. 26\%) [2I].

In our case, as the child had a single normally functioning kidney (other atrophic and non-functioning), we were reluctant to end the procedure with a residual $90 \%$ stenosis following balloon dilatation. For salvaging kidney function, to prevent kidney failure and to hypertension, bailout stenting was performed. Also, in future in the event of restenosis or relative stenosis when the renal artery increases in size, the $5 \mathrm{~mm}$ stent can be further expanded up to $7 \mathrm{~mm}$ by balloon dilatation. Restenosis may also be dealt with cutting balloons or drug-eluting balloons should it occur in future. Like coronary arteries, it is possible that cutting balloon angioplasty could have given a better angiographic result but currently, there is lack of evidence with use of cutting balloons in young children. Also, the upward orientation of the renal artery and the resultant sharp angle vis-a-vis the guide catheter, we decided that stenting was the safest option to salvage the only functioning kidney. Furthermore, renal artery rupture has been reported to occur even in adults following cutting balloon angioplasty [20]. Another option could have been the use of bio-resorbable scaffold (BRS), but the limitation with current generation stents was its diameter as largest available diameter is $3.5 \mathrm{~mm}$. Also, it is associated with increased risk of stent thrombosis [22].

Because of the diffuse, inflammatory and possibly progressive nature of the disease, surgical treatment is not preferred for Takayasu arteritis except for undilatable symptomatic stenotic lesions and for large aneurysms [3].

In view of underlying disease, drug-eluting stents (DES) are the best option [23]. At present, coronary DES are used in the renal arteries as dedicated DES for renal artery are not available. Despite recent randomised trials showing no benefit of renal artery stenting against medical management, the benefit of renal angioplasty 
still remains in selected cases of renal artery stenosis $[24,25]$. Superiorly angulated renal arteries are best approached from below, allowing natural orientation of balloon and stent with the vessel, as was performed in the present case. Also, we pushed the balloon little up during post-dilatation of renal stent to properly flare the upper margin of stent so that it would help in future rewiring had any restenosis will be encountered (Fig. 5B). Our case report highlights the procedural challenge and excellent clinical outcome achieved in a patient with renal artery stenosis with juxtaposed aortic involvement.

\section{Conflict of interest}

None.

\section{References:}

I. Khanna N, Pramesti R, Sinha S, et al. Juvenile Takayasu Arteritis: A case report. Journal of Indian College of Cardiology. 2017; 7(I): 28-30, doi: 10.1016/j.jicc.2017.01.001.

2. Kothari S. Takayasu's arteritis in children - a review. Images Paediatr Cardiol. 200I; 3(4): 4-23, indexed in Pubmed: 22368604.

3. Hahn D, Thomson PD, Kala U, et al. A review of Takayasu's arteritis in children in Gauteng, South Africa. Pediatr Nephrol. 1998; 12(8): 668-675, indexed in Pubmed: 98। 1393.

4. Tyagi S, Kaul UA, Satsangi DK, et al. Percutaneous transluminal angioplasty for renovascular hypertension in children: initial and long-term results. Pediatrics. 1997; 99(1): 44-49, indexed in Pubmed: 8989336.

5. US Department of Health and Human service. National Institute of Health/ National Heart, Lung, and Blood Institute. A Pocket Guide to Blood pressure Measurements in Children. NIH Publication 2007; 07-5268.

6. Ozen S, Ruperto N, Dillon MJ, et al. EULAR/PReS endorsed consensus criteria for the classification of childhood vasculitides. Ann Rheum Dis. 2006; 65(7): 936-94I, doi: 10.1136/ ard.2005.046300, indexed in Pubmed: 1632208I.

7. Seyahi E. Takayasu arteritis: an update. Curr Opin Rheumatol. 2017; 29(I): 5I-56, doi: 10.1097/BOR.00000000000000343, indexed in Pubmed: 27748689.

8. Mukhtyar C, Guillevin L, Cid MC, et al. European Vasculitis Study Group. EULAR recommendations for the management of large vessel vasculitis. Ann Rheum Dis. 2009; 68(3): 318-323, doi: I0. I | 36/ard.2008.08835 I, indexed in Pubmed: |84 |344|.

9. Cheng Y, Lv N, Wang Z, et al. 18-FDG-PET in assessing disease activity in Takayasu arteritis: a meta-analysis. Clin Exp Rheumatol. 2013; 31(I Suppl 75): S22-S27, indexed in Pubmed: 23433014.

10. Papa M, De Cobelli F, Baldissera E, et al. Takayasu arteritis: intravascular contrast medium for MR angiography in the evaluation of disease activity. AJR Am J Roentgenol. 2012; 198(3): W279-W284, doi: 10.2214/AJR.11.7360, indexed in Pubmed: 22358026.

II. Schmidt WA. Imaging in vasculitis. Best Pract Res Clin Rheumatol. 2013; 27(I): 107-II8, doi: 10.1016/j.berh.2013.01.00I, indexed in Pubmed: 23507061.
12. Tezuka D, Haraguchi Go, Ishihara T, et al. Role of FDG PETCT in Takayasu arteritis: sensitive detection of recurrences. JACC Cardiovasc Imaging. 2012; 5(4): 422-429, doi: 10.1016/j. jcmg.2012.01.013, indexed in Pubmed: 22498333.

13. Rao SA, Mandalam KR, Rao VR, et al. Takayasu arteritis: initial and long-term follow-up in 16 patients after percutaneous transluminal angioplasty of the descending thoracic and abdominal aorta. Radiology. 1993; 189(1): 173-179, doi: 10.1148/ radiology. 189.1.8103942, indexed in Pubmed: 8103942.

14. Kim HJ, Lee CS, Kim JS, et al. Outcomes after endovascular treatment of symptomatic patients with Takayasu's arteritis. Interv Neuroradiol. 201I; 17(2): 252-260, doi: 10.1177/159101991101700219, indexed in Pubmed: 21696668.

15. Khandelwal N, Kalra N, Garg MK, et al. Multidetector CT angiography in Takayasu arteritis. Eur J Radiol. 20II; 77(2): 369-374, doi: 10.1016/j.ejrad.2009.08.00I, indexed in Pubmed: 19720487.

16. Dagna L, Salvo F, Tiraboschi M, et al. Pentraxin-3 as a marker of disease activity in Takayasu arteritis. Ann Intern Med. 201 I; 155(7): 425-433, doi: 10.7326/0003-48|9-155-7-201 I 1004000005, indexed in Pubmed: 2196934I.

17. Bali HK, Jain $S$, Jain $A$, et al. Stent supported angioplasty in Takayasu arteritis. International Journal of Cardiology. 1998; 66: S2I3-S217, doi: 10.1016/s0167-5273(98)00171-5.

18. Colyer JH, Ratnayaka K, Slack MC, et al. Renal artery stenosis in children: therapeutic percutaneous balloon and stent angioplasty. Pediatr Nephrol. 2014; 29(6): 1067-1074, doi: 10.1007/ s00467-013-2730-2, indexed in Pubmed: 24445432.

19. Zhu G, He F, Gu Y, et al. Angioplasty for pediatric renovascular hypertension: a I3-year experience. Diagn Interv Radiol. 2014; 20(3): 285-292, doi: 10.5152/dir.2014.13208, indexed in Pubmed: 24675165.

20. Shroff R, Roebuck DJ, Gordon I, et al. Angioplasty for renovascular hypertension in children: 20-year experience. Pediatrics. 2006; I I8(I): 268-275, doi: 10.1542/peds.2005-2642, indexed in Pubmed: 16818574 .

21. Leertouwer TC, Gussenhoven EJ, Bosch JL, et al. Stent placement for renal arterial stenosis: where do we stand? A meta-analysis. Radiology. 2000; 216 (I): 78-85, doi: 10.1 I48/radiology.216.1.r00j10778, indexed in Pubmed: 10887230.

22. Dudek D, Onuma $Y$, Ormiston JA, et al. Four-year clinical follow-up of the ABSORB everolimus-eluting bioresorbable vascular scaffold in patients with de novo coronary artery disease: the ABSORB trial. Eurolntervention. 2012; 7(9): 1060-106I, doi: 10.4244/EIJV7I9A 168, indexed in Pubmed: 21959320.

23. Ahn J, Park SH, Shin WY, et al. Use of drug-eluting stent with provisional T-stenting technique in the treatment of renal artery bifurcation stenosis; long-term angiographic follow-up. J Korean Med Sci. 20II; 26(II): 15I2-15I4, doi: 10.3346/ jkms.20II.26.1 I.15I2, indexed in Pubmed: 220659I0.

24. Wheatley K, Ives N, Gray R, et al. ASTRAL Investigators. Revascularization versus medical therapy for renal-artery stenosis. N Engl J Med. 2009; 36I(20): 1953-1962, doi: 10.1056/NEJMoa0905368, indexed in Pubmed: 19907042.

25. Cooper CJ, Murphy TP, Cutlip DE, et al. CORAL Investigators. Stenting and medical therapy for atherosclerotic renal-artery stenosis. N Engl J Med. 20 I4; 370(1): 13-22, doi: 10. 1056/NEJMoal 310753 , indexed in Pubmed: 24245566. 